\title{
Epithelial cell-adhesion molecule-directed trifunctional antibody immunotherapy for symptom management of advanced ovarian cancer
}

\author{
This article was published in the following Dove Press journal: \\ Clinical Pharmacology:Advances and Applications \\ 2 October 2013 \\ Number of times this article has been viewed
}

\author{
Ramez N Eskander \\ Krishnansu S Tewari \\ Division of Gynecologic Oncology, \\ Department of Obstetrics and \\ Gynecology, University of California, \\ Irvine, CA, USA
}

\begin{abstract}
Despite advances in cytotoxic chemotherapy and surgical cytoreduction, disease recurrence continues to be a troubling problem in patients with advanced-stage epithelial ovarian cancer (EOC). Malignant ascites affects approximately $10 \%$ of patients with recurrent EOC and is associated with troublesome symptoms, including abdominal pressure, distension, dyspnea, pelvic pain, and bowel/bladder dysfunction. To date, no effective therapy has been identified for the treatment of malignant ascites in patients with recurrent, advanced-stage ovarian cancer. Recently, immune modulation has gained attention as a novel approach to anti-cancer therapy. This review explores the role of epithelial cell-adhesion molecule (EpCAM)-directed immunotherapy, with a specific focus on the mechanism of action of the trifunctional antibody catumaxomab (anti-EpCAM $\times$ anti-CD3). In addition, clinical trials exploring the use of catumaxomab in the treatment of malignant ascites in patients with ovarian cancer are reviewed.
\end{abstract}

Keywords: ovarian cancer, immunotherapy, catumaxomab, CD3, EpCAM

\section{Introduction}

Epithelial ovarian cancer (EOC) accounts for 25\% of all malignancies affecting the female genital tract, and is the most lethal gynecologic malignancy. In 2013 there will be an estimated 22,240 new ovarian cancer cases in the USA, with 14,030 deaths. ${ }^{1}$ Advanced-stage EOC is traditionally managed with cytoreductive surgery, followed by combination platinum- and taxane-based chemotherapy. ${ }^{2}$ Despite aggressive treatment, the majority of these patients develop recurrent cancer, with selection of chemotherapy-resistant clones. ${ }^{3}$ The subset of patients who develop recurrent disease is a population that traditionally faces extended exposure to multiple cytotoxic chemotherapy regimens, dictated by their disease-free interval. ${ }^{4-7}$ Throughout this period, management of disease-associated morbidities becomes a priority in an effort to improve quality of life.

Malignant ascites, which affects approximately two-thirds of patients with EOC, primary peritoneal cancer (PPC), and fallopian tube cancer (FTC), is common, and to date few effective therapies have been identified..$^{8,9}$ Importantly, ascites is associated with troublesome symptoms, including abdominal pressure and distension, dyspnea, pelvic pain, and bowel/bladder dysfunction. ${ }^{10}$ Historically, malignant ascites in patients with EOC was treated utilizing diuretics and salt restriction, as well as intraperitoneal administration of sclerosing agents and radioactive isotopes. ${ }^{11,12}$ Patients with malignant ascites secondary to EOC rarely suffer from fluid accumulation due to
Correspondence: Krishnansu S Tewar Division of Gynecologic Oncology, Department of Obstetrics and Gynecology, University of California, Irvine, I0I The City Drive South, Building 56, Suite 260, Orange, CA 92868, USA

Fax +I 7I4 4566632

Email ktewari@uci.edu 
intraparenchymal liver metastasis, and portal hypertension is uncommonly identified. Rather, these patients traditionally exhibit reduced intravascular volume, making diuretic use an unattractive option. ${ }^{13}$ With respect to the use of radioactive isotopes, poor tumor penetration and intestinal toxicity (necrosis and perforation) due to loculations and prolonged exposure have caused them to fall out of favor. Limited success rates, in combination with significant side effects, have resulted in the infrequent use of these modalities.

Mechanical drainage of accumulated ascitic fluid via therapeutic paracentesis results in relief in up to $90 \%$ of patients. ${ }^{14}$ However, recurrence/reaccumulation of ascites is common, and multiple paracentesis are required, with their associated risks of pain, visceral perforation, infection, and hematoma formation. ${ }^{15,16}$ Furthermore, these patients are likely to have intra-abdominal adhesions as a result of their extensive surgical cytoreduction, and the resultant fluid loculations limit the therapeutic benefit derived. ${ }^{17}$ Alternatively, placement of permanent intra-abdominal drains and peritoneovenous shunts has been explored. Experience with these modalities has been poor, as blockage of the shunt, infectious morbidity, as well as embolization and implantation of tumor cells in distant organs, were reported to be relatively common complications. ${ }^{12,18-21}$

Unlike other solid malignancies, where ascites portends a universally poor prognosis, patients with EOC and ascites at the time of diagnosis can expect 5-year survival rates approaching $40 \% .^{15,22}$ This discrepancy is largely attributable to the biology of ovarian cancer, and the subsequent etiology of the abdominal fluid accumulation. Specifically, malignant ascites in patients with EOC is thought to be attributable to (1) lymphatic obstruction, (2) increased vascular permeability, (3) release of inflammatory cytokines, and (4) direct increase of fluid production by the cancer cells lining the peritoneal cavity. ${ }^{9,23-25}$

Given the above, exploration into immune modulation as a novel anti-cancer approach for the treatment of malignant ascites in patients with advanced-stage EOC has been a clinical priority. ${ }^{9}$ Tumor immunology is complex, as activation of the immune system requires presentation of a foreign antigen via antigen-presenting cells (APCs) to T-cells. ${ }^{26}$ In normal immune responses, the cytotoxic effects are driven by a combination of T-lymphocyte activity, antibody-dependent mechanisms, and natural killer (NK) cell activation. ${ }^{26-28}$

Tumor cell destruction by tumor antigen-specific $\mathrm{T}$ lymphocytes has been demonstrated in vitro for a variety of both solid and hematologic malignancies. Certain cytokines, including interferon $\gamma$ and tumor necrosis factor (TNF), are essential components of the above response. Conversely, antibody-mediated cytotoxicity relies on direct antibody binding to tumor cell surfaces, and the subsequent recruitment of granulocytes and macrophages, both of which contain surface receptors for the fragment crystallizable (Fc) portion of the antibody. Analogously, activated NK cells contain surface receptors for antibody Fc regions, and participate in antibody-mediated cytotoxicity. Furthermore, activated NK cells secrete TNF- $\alpha$, inducing hemorrhage and tumor necrosis.

Unfortunately, tumor cells have adapted to escape immune destruction, utilizing tumor-related and host-related mechanisms. Cancer cells may fail to provide an antigenic target due to lack of an antigenic (foreign) epitope, lack of major histocompatibility complex-I molecule, or via antigenic modulation and tumor masking. ${ }^{29,30}$ Host-related mechanisms include immune suppression, regulatory T-cell (Treg) suppression of tumor immunity, deficient epitope expression by host APCs, and failure of host immune cells to reach the tumor due to stromal barriers. ${ }^{31}$

\section{Ovarian cancer immunology}

An increasingly robust body of literature supports the contribution of immune cells in both ovarian cancer therapeutics and pathogenesis. ${ }^{32-42}$ In 1988, immune studies performed on ovarian cancer specimens confirmed the presence of tumorinfiltrating lymphocytes (TILs). ${ }^{43}$ Cluster of differentiation 3 (CD3)+ TILs have been found to independently predict tumor recurrence and prolonged survival. ${ }^{42}$ Conversely, lack of TILs has been associated with poor survival. . $^{34,36-40}$

Certain subsets of T-cells exhibit a pro-cancer effect. Treg infiltration has been associated with higher cancer grade and advanced surgical stage. ${ }^{44}$ Additionally, increasing numbers of circulatory Tregs identified in peripheral blood samples have been linked to disease progression..$^{45}$ These CD4+CD25+ Tregs are hypothesized to mitigate the immune response via two distinct mechanisms, inhibiting both cellcell contact and interleukin-2 transcription. ${ }^{31}$

The impact of B-cell function on cancer immunology has been more difficult to discern as a result of conflicting data. ${ }^{46-49}$

\section{Epithelial cell-adhesion molecule (EpCAM)}

Epithelial cell-adhesion molecule (EpCAM) is a calciumindependent transmembrane, glycoprotein cell-adhesion molecule, with a molecular weight of 39-42 kDa. ${ }^{50}$ Traditionally, it is expressed in normal epithelium, with the 
exception of squamous epithelium, epidermal keratinocytes, gastric parietal cells, myoepithelial cells, thymic cortical epithelium, and hepatocytes. ${ }^{51,52}$ EpCAM is abundantly expressed on human cancers, and was first described as a dominant antigen in patients with colon carcinoma. ${ }^{53,54}$ Since then, EpCAM overexpression has been associated with poor prognosis in patients with ovarian, breast, prostate, and gallbladder carcinoma, both functioning as an oncogene and suppressing CD4+ T-cell-dependent immune responses. ${ }^{55-58}$

Initial interest in the utilization of EpCAM as a target for active immunotherapy emerged following a seminal publication reporting anti-tumor effects with the EpCAMspecific monoclonal antibody edrecolomab in patients with metastatic colorectal cancer. ${ }^{58,59}$ Despite initial promise, the therapeutic impact of this approach was found to be inferior to traditional cytotoxic chemotherapy regimens in colon cancer patients.

With respect to ovarian cancer, EpCAM expression has been demonstrated in the main histotypes, and is well documented in microarray studies. ${ }^{60}$ In a study of 21 biomarkers in four distinct ovarian cancer subtypes (high-grade serous, clear cell, endometrioid, mucinous), only EpCAM exhibited consistent high expression. ${ }^{60}$ Furthermore, data indicate that EpCAM appears to be a stable antigen in ovarian cancer patients, with preserved expression levels in primary, recurrent, and metastatic specimens, as well as malignant ascites and effusions. ${ }^{61,62}$

\section{The trifunctional antibody catumaxomab (anti-EpCAM $\times$ anti-CD3)}

In an effort to circumvent the limitations initially encountered with monoclonal antibodies (mAb), bispecific antibodies, which allow for simultaneous binding of both T-cell and accessory cells, were designed and tested. Ultimately, the design of trifunctional antibodies allowed for combination of two distinct anti-tumor functionalities (T-cell-mediated death and accessory cells). ${ }^{27,63,64}$

Catumaxomab is a trifunctional $\mathrm{mAb}$ with two different antigen-binding sites and a functional Fc domain (Figure 1). ${ }^{65,66} \mathrm{It}$ is composed of a mouse $\kappa$ light chain, a rat $\lambda$ light chain, a mouse immunoglobulin (Ig)-G2a heavy chain, and a rat IgG2a heavy chain. The two specific antigen-binding sites bind to epithelial tumor cells via the EpCAM and to T-cells via CD3. In addition, catumaxomab activates Fc $\gamma$ receptor I-, IIa-, and III-positive accessory cells (dendritic cells [DCs], macrophages, and NK cells) via its functional Fc domain, resulting in a comprehensive and complex immune reaction (Figure 1). ${ }^{65,66}$

The functionality and selectivity of this novel antibody rely on the fact that tumor cells in malignant ovarian cancerassociated ascites have been shown to express EpCAM in $70 \%-100 \%$ of cases, while the mesothelial cells lining the peritoneal cavity lack expression. ${ }^{67}$ Following EpCAM binding, catumaxomab results in recruitment and activation of immune effector cells, resulting in its antineoplastic activity. The two unique antibody-antigen binding sites of the trifunctional antibody enable recognition of both T-cells and tumor cells. The functional Fc domain can then activate neighboring Fc $\gamma$-receptor-positive macrophages, DCs, and NK cells, as described by Eissler et al in elegant animal model experiments. ${ }^{68}$ Ultimately, tumor cell death results from cell lysis via perforin/granzyme-B, antibody-mediated cell death, and phagocytosis. ${ }^{66,69,70}$

Catumaxomab has also been shown to induce anti-tumor immunity in animal models and in patients with peritoneal carcinomatosis. In a study conducted by Ströhlein and Heiss
A

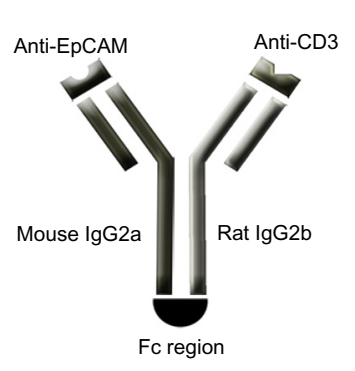

B

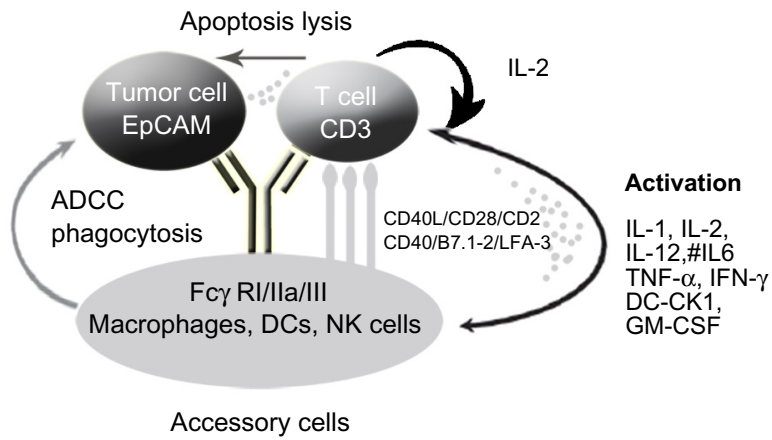

Figure I Schematic of the structure and mode of action of catumaxomab. (A) Catumaxomab is a trifunctional monoclonal antibody with two different antigen-binding sites and a functional Fc domain. (B) The two specific antigen-binding sites bind to epithelial tumor cells via the EpCAM and to T-cells via CD3, while activating Fc $\gamma$-receptor I-, Ila-, and III-positive accessory cells (dendritic cells, macrophages, and NK cells) via its functional Fc domain.

Abbreviations: CD3, cluster of differentiation 3; DCs, dendritic cells; EpCAM, epithelial cell-adhesion molecule; Fc, fragment crystallizable; IgG, immunoglobulin; NK, natural killer; IL, interleukin; INF, interferon; GM-CSF, granulocyte macrophage colony stimulating factor; ADCC, antibody dependent cell mediated cytotoxicity; DC-CKI, dendritic cell CKI. 
, tumor-reactive CD4+/CD8+ T-cells were induced after an initial treatment course with escalating doses of trifunctional antibodies, followed by re-stimulation 4 weeks after completion of initial treatment. ${ }^{71-73}$

\section{Catumaxomab in the treatment of ovarian cancer ascites (anti-EpCAM $\times$ anti-CD3)}

Malignant ascites affects approximately $10 \%$ of patients with recurrent EOC and is associated with troublesome symptoms. Intraperitoneal administration of catumaxomab was first studied in the treatment of eight patients (two of whom had ovarian cancer) with malignant ascites in $2005 .{ }^{74}$ All patients had $>2 \%$ EpCAM expression via flow cytometry, on nuclear ascites cells. Trifunctional antibodies were administered intraperitoneally over 6-8 hours, for at least four cycles. Seven of eight patients required no further paracentesis during follow-up or until death, with a mean paracentesis-free interval of 38 weeks (median 21.5, range 4-136). Clinical response, with disappearance of ascites accumulation, was seen in all patients, which was correlated with elimination of tumor cells $(P=0.0014){ }^{74}$

Following this study, a multicenter phase I/II clinical trial was conducted evaluating the tolerability and efficacy of intraperitoneal catumaxomab in ovarian cancer patients with malignant ascites containing EpCAM-positive tumor cells. ${ }^{75}$ Twenty-three women with recurrent ascites due to pretreated refractory ovarian cancer were treated with four to five intraperitoneal infusions of catumaxomab in doses of 5,200 $\mu \mathrm{g}$ within 913 days. Treatment with catumaxomab resulted in significant and sustained reduction of ascites. Of the 23 patients, 22 did not require paracentesis between the last infusion and the end of study at day $37 .^{75}$ The most commonly reported grade $2 / 3$ adverse events in the study included fever, nausea, and vomiting.

Recently, a prospective, randomized phase II/III study was conducted comparing the efficacy of catumaxomab plus paracentesis with paracentesis alone in the treatment of malignant ascites. ${ }^{67}$ Following paracentesis, catumaxomab was administered at doses of $10,20,50$, and $150 \mu \mathrm{g}$ on days $0,3,7$, and 10 , respectively, via an intraperitoneal catheter. The primary efficacy endpoint was puncture-free survival. Secondary efficacy parameters included time to next paracentesis, ascites signs and symptoms, and overall survival (OS). Puncture-free survival was significantly longer in the catumaxomab group (median 46 days) than in the control group (median 11 days) (hazard ratio [HR] $0.254 ; P<0.0001)$, as was median time to next paracentesis
(77 versus 13 days; $P<0.0001$ ). Within the ovarian cancer cohort, median puncture-free survival was 52 days in the catumaxomab arm versus 11 days in the placebo arm (HR 0.205; $P<0.0001)$. In addition, catumaxomab-treated patients had fewer signs and symptoms of ascites than control patients. The most common adverse events included fever, abdominal pain, nausea, and vomiting. One patient had a grade 3 gastric hemorrhage. Findings from the above trials ultimately resulted in the European Medicines Agency approval of catumaxomab for the treatment of malignant ascites in patients with EpCAM-positive tumors for whom no standard therapy is available. ${ }^{23}$

Immunomonitoring studies performed as part of the clinical trial were notable for a significant decline in EpCAMpositive tumor cells from a median screening value of 6,510 EpCAM-positive cells (165 patients) to a median of 27 cells on day 3 (133 patients), and to 0 cells (115 patients) on day 11 in the catumaxomab-treated arm. ${ }^{76}$ In the control group, the tumor cell number increased from 9,373 EpCAMpositive tumor cells at screening (85 patients) to 18,929 EpCAM-positive tumor cells (74 patients) at the puncture visit. Furthermore, catumaxomab treatment was associated with a significant decline $(63 \% ; P<0.001)$ in ascites fluid levels of vascular endothelial growth factor (VEGF), inhibiting vascular permeability, translating into decreased ascites fluid production. Lastly, CD69+ (indicative of lymphocyte proliferation), $\mathrm{CD} 4+$, and $\mathrm{CD} 8+\mathrm{T}$-cell populations increased more than 2-fold in catumaxomab-treated subjects. The activation of peritoneal T-cells and concomitant decline in EpCAM-positive tumor cells establishes a cellular basis for the anti-tumor immunologic effects of the trifunctional antibody catumaxomab. ${ }^{76}$

The palliative nature of the treatment of malignant ascites in patients with recurrent ovarian cancer necessitates prioritization of quality of life during treatment. Wimberger et al conducted a post-trial ad hoc analysis of the above-described phase II/III study to determine the impact of catumaxomab on health-related quality of life (HR-QOL). ${ }^{77}$ Deterioration in QOL scores appeared more rapidly in the control than in the catumaxomab group (median 19-26 days versus 47-49 days). The difference in time to deterioration in QOL between the groups was statistically significant for all scores $(P<0.01)$.

The chronicity of disease in patients with recurrent malignant ascites related to ovarian carcinoma led to the exploration of intraperitoneal changes resulting from treatment with catumaxomab. In a small retrospective series, ten patients previously treated with intraperitoneal catumaxomab 
underwent repeat surgical exploration for secondary cytoreduction, treatment of anastomotic leaks or ileus, or for colostomy reversal. ${ }^{78}$ Catumaxomab treatment was associated with severe intra-abdominal adhesions, grade 3. Conversely, no patients had ascites volume $>500 \mathrm{~mL}$ despite extensive carcinomatosis in eight of ten subjects.

Given the mouse-rat origin of catumaxomab, limitations in retreatment were anticipated due to formation of human anti-drug antibodies (HADA). However, in 2011, Pietzner et al described a case of successful re-treatment with catumaxomab for the management of malignant ascites. ${ }^{79}$ A 74-year-old female patient with breast cancer and peritoneal carcinomatosis-associated ascites was treated with catumaxomab, with resolution of her symptoms. The patient remained puncture free for 45 days, and evaluation of HADA levels demonstrated increased levels after cycle 1 , followed by a considerable decline and delayed increase in ascites HADA levels for each subsequent cycle. This experience suggested that a repeat cycle of catumaxomab might be feasible and effective in patients suffering from recurrent malignant effusions.

More recently, Ott et $\mathrm{al}^{80}$ conducted a post-trial ad hoc analysis in order to determine the impact of human antimouse antibodies (HAMA) levels 8 days after the last infusion on clinical outcomes in patients treated on the European Union Drug Regulating Authorities Clinical Trials (EudraCT) clinical trial (NCT00836654). ${ }^{81}$ There was a strong correlation between humoral response and clinical outcome, with HAMA-positive patients showing improvement in median puncture-free survival, median time to next therapeutic puncture, as well as median OS. ${ }^{80}$ Specifically, median OS in HAMA-positive ovarian cancer patients was 163 days, compared with 82 days in the HAMA-negative patients $(P=0.0123$; HR 0.407). This finding remained significant in both the intention-to-treat and per-protocol analysis.

\section{Conclusion}

Despite aggressive surgical cytoreduction and adjuvant chemotherapy, disease recurrence continues to be problematic for patients with advanced-stage EOC. Immune modulation has gained significant attention in recent years as a novel anti-cancer approach. Catumaxomab is an innovative trifunctional antibody that relies on direct tumor cell and T-cell binding while simultaneously recruiting accessory immune cells to treat malignant ascites. This complex association results in tumor cell kill and simultaneously induces a humoral immune response. Currently, additional trials are being conducted to explore the safety of a 3-hour infusion of catumaxomab in conjunction with steroid premedication (Catumaxomab Safety Phase IIIb Study With Intraperitoneal Infusion in Patients with Malignant Ascites Due to Epithelial Cancers [CASIMAS]), ${ }^{82}$ as well as the safety of re-treatment with intraperitoneal catumaxomab (Safety Study of Second Intraperitoneal Infusion Cycle of Catumaxomab in Patients With Malignant Ascites [SECIMAS]). ${ }^{83}$ Additionally, phase I/II clinical trials exploring combination treatment using catumaxomab and traditional cytotoxic chemotherapy are required, to determine if there is therapeutic efficacy to combined treatment. The ENGOTov8 study, ${ }^{84}$ a multicenter prospective phase II clinical trial, is currently open, and is exploring the feasibility and clinical activity of intraperitoneal catumaxomab followed by systemic intravenous chemotherapy in patients with recurrent ovarian cancer.

Ultimately, as with all novel therapies, symptom relief and treatment goals must be weighed against patient discomfort and adverse events. Careful patient selection, and identification of risk factors, to help reduce significant side effects associated with treatment are required.

\section{Disclosure}

The authors have no conflicts of interest to disclose.

\section{References}

1. Siegel R, Naishadham D, Jemal A. Cancer statistics, 2013. CA Cancer J Clin. 2013;63(1):11-30.

2. Bookman MA. Trials with impact on clinical management: first line. Int J Gynecol Cancer. 2009;19 Suppl 2:S55-S62.

3. Monk BJ, Choi DC, Pugmire G, Burger RA. Activity of bevacizumab (rhuMAB VEGF) in advanced refractory epithelial ovarian cancer. Gynecol Oncol. 2005;96(3):902-905.

4. Cannistra SA. Evaluating new regimens in recurrent ovarian cancer: how much evidence is good enough? J Clin Oncol. 2010;28(19): 3101-3103.

5. Pujade-Lauraine E, Wagner U, Aavall-Lundqvist E, et al. Pegylated liposomal doxorubicin and carboplatin compared with paclitaxel and carboplatin for patients with platinum-sensitive ovarian cancer in late relapse. J Clin Oncol. 2010;28(20):3323-3329.

6. Cannistra SA. Is there a "best" choice of second-line agent in the treatment of recurrent, potentially platinum-sensitive ovarian cancer? J Clin Oncol. 2002;20(5):1158-1160.

7. Eskander RN, Randall LM. Bevacizumab in the treatment of ovarian cancer. Biologics. 2011;5:1-5.

8. Malayev Y, Levene R, Gonzalez F. Palliative chemotherapy for malignant ascites secondary to ovarian cancer. Am J Hosp Palliat Care. 2012;29(7):515-521.

9. Eskander RN, Tewari KS. Emerging treatment options for management of malignant ascites in patients with ovarian cancer. Int $J$ Womens Health. 2012;4:395-404.

10. Loggie BW, Perini M, Fleming RA, Russell GB, Geisinger K. Treatment and prevention of malignant ascites associated with disseminated intraperitoneal malignancies by aggressive combined-modality therapy. Am Surg. 1997;63(2):137-143.

11. Qazi R, Savlov ED. Peritoneovenous shunt for palliation of malignant ascites. Cancer. 1982;49(3):600-602. 
12. Ariel IM, Oropeza R, Pack GT. Intracavitary administration of radioactive isotopes in the control of effusions due to cancer. Results in 267 patients. Cancer. 1966;19(8):1096-1102.

13. Runyon BA. Care of patients with ascites. N Engl J Med. 1994;330(5): 337-342.

14. Gotlieb WH, Feldman B, Feldman-Moran O, et al. Intraperitoneal pressures and clinical parameters of total paracentesis for palliation of symptomatic ascites in ovarian cancer. Gynecol Oncol. 1998;71(3):381-385.

15. Barni S, Cabiddu M, Ghilardi M, Petrelli F. A novel perspective for an orphan problem: old and new drugs for the medical management of malignant ascites. Crit Rev Oncol Hematol. 2011;79(2):144-153.

16. Becker G, Galandi D, Blum HE. Malignant ascites: systematic review and guideline for treatment. Eur J Cancer. 2006;42(5):589-597.

17. Keen A, Fitzgerald D, Bryant A, Dickinson HO. Management of drainage for malignant ascites in gynaecological cancer. Cochrane Database Syst Rev. 2010;(1):CD007794.

18. Stark RH, Sauter KE. Surgical treatment of adenocarcinoma of the stomach in a community hospital. Surg Gynecol Obstet. 1985;160(2): 153-156.

19. Ostrowski MJ, Halsall GM. Intracavitary bleomycin in the management of malignant effusions: a multicenter study. Cancer Treat Rep. 1982;66(11):1903-1907.

20. Maat B, Oosterlee J, Spaas JA, White H, Lammes FB. Dissemination of tumour cells via LeVeen shunt. Lancet. 1979;1(8123):988.

21. Paladine W, Cunningham TJ, Sponzo R, Donavan M, Olson K, Horton J. Intracavitary bleomycin in the management of malignant effusions. Cancer. 1976;38(5):1903-1908.

22. Jemal A, Siegel R, Xu J, Ward E. Cancer statistics, 2010. CA Cancer J Clin. 2010;60(5):277-300.

23. Becker G, Blum HE. VEGF Trap for the treatment of malignant ascites. Lancet Oncol. 2012;13(2):115-116.

24. Garrison RN, Galloway RH, Heuser LS. Mechanisms of malignant ascites production. J Surg Res. 1987;42(2):126-132.

25. Tsikouras $\mathrm{P}, \mathrm{T}$ sagias $\mathrm{N}$, Pinidis $\mathrm{P}$, et al. The contribution of catumaxomab in the treatment of malignant ascites in patients with ovarian cancer: a review of the literature. Arch Gynecol Obstet. Epub May 5, 2013.

26. Thibodeaux SR, Curiel TJ. Immune therapy for ovarian cancer: promise and pitfalls. Int Rev Immunol. 2011;30(2-3):102-119.

27. Staerz UD, Kanagawa O, Bevan MJ. Hybrid antibodies can target sites for attack by T cells. Nature. 1985;314(6012):628-631.

28. Melief CJ, Finn OJ. Cancer immunology. Curr Opin Immunol. 2011;23(2):234-236.

29. Strainic MG, Shevach EM, An F, Lin F, Medof ME. Absence of signaling into $\mathrm{CD}^{+}$cells via $\mathrm{C} 3 \mathrm{aR}$ and $\mathrm{C} 5 \mathrm{aR}$ enables autoinductive TGF- $\beta 1$ signaling and induction of Foxp $3^{+}$regulatory T cells. Nature Immunol. 2013;14(2):162-171.

30. Hodi FS, Mihm MC, Soiffer RJ, et al. Biologic activity of cytotoxic T lymphocyte-associated antigen 4 antibody blockade in previously vaccinated metastatic melanoma and ovarian carcinoma patients. Proc Natl Acad Sci U S A. 2003;100(8):4712-4717.

31. Pasare C, Medzhitov R. Toll pathway-dependent blockade of CD4+CD25+ T cell-mediated suppression by dendritic cells. Science. 2003;299(5609):1033-1036.

32. Stumpf M, Hasenburg A, Riener MO, et al. Intraepithelial CD8-positive T lymphocytes predict survival for patients with serous stage III ovarian carcinomas: relevance of clonal selection of T lymphocytes. $\mathrm{Br} \mathrm{J}$ Cancer. 2009;101(9):1513-1521.

33. Nagata Y, Hanagiri T, Mizukami M, et al. Clinical significance of HLA class I alleles on postoperative prognosis of lung cancer patients in Japan. Lung Cancer. 2009;65(1):91-97.

34. Leffers N, Gooden MJ, de Jong RA, et al. Prognostic significance of tumor-infiltrating T-lymphocytes in primary and metastatic lesions of advanced stage ovarian cancer. Cancer Immunol Immunother. 2009;58(3):449-459.

35. Jang KY, Kim KS, Hwang SH, et al. Expression and prognostic significance of SIRT1 in ovarian epithelial tumours. Pathology. 2009;41(4): 366-371.
36. Clarke $\mathrm{B}$, Tinker AV, Lee $\mathrm{CH}$, et al. Intraepithelial T cells and prognosis in ovarian carcinoma: novel associations with stage, tumor type, and BRCA1 loss. Mod Pathol. 2009;22(3):393-402.

37. Adams SF, Levine DA, Cadungog MG, et al. Intraepithelial T cells and tumor proliferation: impact on the benefit from surgical cytoreduction in advanced serous ovarian cancer. Cancer. 2009;115(13):2891-2902.

38. Han LY, Fletcher MS, Urbauer DL, et al. HLA class I antigen processing machinery component expression and intratumoral T-cell infiltrate as independent prognostic markers in ovarian carcinoma. Clin Cancer Res. 2008;14(11):3372-3379.

39. Callahan MJ, Nagymanyoki Z, Bonome T, et al. Increased HLA-DMB expression in the tumor epithelium is associated with increased CTL infiltration and improved prognosis in advanced-stage serous ovarian cancer. Clin Cancer Res. 2008;14(23):7667-7673.

40. Hamanishi J, Mandai M, Iwasaki M, et al. Programmed cell death 1 ligand 1 and tumor-infiltrating CD8+T lymphocytes are prognostic factors of human ovarian cancer. Proc Natl Acad Sci U S A. 2007;104(9): 3360-3365.

41. Sato E, Olson SH, Ahn J, et al. Intraepithelial CD8+ tumor-infiltrating lymphocytes and a high $\mathrm{CD} 8+/$ regulatory $\mathrm{T}$ cell ratio are associated with favorable prognosis in ovarian cancer. Proc Natl Acad Sci USA. 2005;102(51):18538-18543.

42. Zhang L, Conejo-Garcia JR, Katsaros D, et al. Intratumoral T cells, recurrence, and survival in epithelial ovarian cancer. $N$ Engl J Med. 2003;348(3):203-213.

43. Heo DS, Whiteside TL, Kanbour A, Herberman RB. Lymphocytes infiltrating human ovarian tumors. I. Role of Leu-19 (NKH1)-positive recombinant IL-2-activated cultures of lymphocytes infiltrating human ovarian tumors. J Immunol. 1988;140(11):4042-4049.

44. Barnett JC, Bean SM, Whitaker RS, et al. Ovarian cancer tumor infiltrating T-regulatory (T(reg)) cells are associated with a metastatic phenotype. Gynecol Oncol. 2010;116(3):556-562.

45. Fialová A, Partlová S, Sojka L, et al. Dynamics of T-cell infiltration during the course of ovarian cancer: the gradual shift from a Th17 effector cell response to a predominant infiltration by regulatory T-cells. Int J Cancer. 2013;132(5):1070-1079.

46. Milne K, Köbel M, Kalloger SE, et al. Systematic analysis of immune infiltrates in high-grade serous ovarian cancer reveals CD20, FoxP3 and TIA-1 as positive prognostic factors. PloS One. 2009;4(7):e6412.

47. Nelson BH. CD20+ B cells: the other tumor-infiltrating lymphocytes. J Immunol. 2010;185(9):4977-4982.

48. Shah S, Divekar AA, Hilchey SP, et al. Increased rejection of primary tumors in mice lacking B cells: inhibition of anti-tumor CTL and TH1 cytokine responses by B cells. Int J Cancer. 2005;117(4):574-586.

49. Yang C, Lee H, Jove V, et al. Prognostic significance of B-cells and pSTAT3 in patients with ovarian cancer. PloS One. 2013;8(1): e54029.

50. Litvinov SV, Bakker HA, Gourevitch MM, Velders MP, Warnaar SO. Evidence for a role of the epithelial glycoprotein 40 (Ep-CAM) in epithelial cell-cell adhesion. Cell Adhes Commun. 1994;2(5):417-428.

51. Schmelzer E, Reid LM. EpCAM expression in normal, non-pathological tissues. Front Biosci. 2008;13:3096-3100.

52. Spizzo G, Fong D, Wurm M, et al. EpCAM expression in primary tumour tissues and metastases: an immunohistochemical analysis. J Clin Pathol. 2011;64(5):415-420.

53. Herlyn M, Steplewski Z, Herlyn D, Koprowski H. Colorectal carcinomaspecific antigen: detection by means of monoclonal antibodies. Proc Natl Acad Sci U S A. 1979;76(3):1438-1442.

54. Patriarca C, Macchi RM, Marschner AK, Mellstedt H. Epithelial cell adhesion molecule expression (CD326) in cancer: a short review. Cancer Treat Rev. 2012;38(1):68-75.

55. Gastl G, Spizzo G, Obrist P, Dünser M, Mikuz G. Ep-CAM overexpression in breast cancer as a predictor of survival. Lancet. 2000;356(9246): 1981-1982.

56. Gutzmer R, Li W, Sutterwala S, et al. A tumor-associated glycoprotein that blocks MHC class II-dependent antigen presentation by dendritic cells. J Immunol. 2004;173(2):1023-1032. 
57. Munz M, Kieu C, Mack B, Schmitt B, Zeidler R, Gires O. The carcinoma-associated antigen EpCAM upregulates c-myc and induces cell proliferation. Oncogene. 2004;23(34):5748-5758.

58. Spizzo G, Went P, Dirnhofer S, et al. Overexpression of epithelial cell adhesion molecule (Ep-CAM) is an independent prognostic marker for reduced survival of patients with epithelial ovarian cancer. Gynecol Oncol. 2006;103(2):483-488.

59. Fagerberg J, Hjelm AL, Ragnhammar P, Frödin JE, Wigzell H, Mellstedt $\mathrm{H}$. Tumor regression in monoclonal antibody-treated patients correlates with the presence of anti-idiotype-reactive $\mathrm{T}$ lymphocytes. Cancer Res. 1995;55(9):1824-1827.

60. Köbel M, Kalloger SE, Boyd N, et al. Ovarian carcinoma subtypes are different diseases: implications for biomarker studies. PLoS Med. 2008;5(12):e232.

61. Bellone S, Siegel ER, Cocco E, et al. Overexpression of epithelial cell adhesion molecule in primary, metastatic, and recurrent/chemotherapyresistant epithelial ovarian cancer: implications for epithelial cell adhesion molecule-specific immunotherapy. Int $J$ Gynecol Cancer. 2009;19(5):860-866.

62. Shetye J, Frödin JE, Christensson B, et al. Immunohistochemical monitoring of metastatic colorectal carcinoma in patients treated with monoclonal antibodies (MAb 17-1A). Cancer Immunol Immunother. 1988;27(2):154-162.

63. Chames P, Baty D. Bispecific antibodies for cancer therapy: the light at the end of the tunnel? mAbs. 2009;1(6):539-547.

64. Chames P, Baty D. Bispecific antibodies for cancer therapy. Curr Opin Drug Discov Devel. 2009;12(2):276-283.

65. Ruf $\mathrm{P}$, Lindhofer $\mathrm{H}$. Induction of a long-lasting antitumor immunity by a trifunctional bispecific antibody. Blood. 2001;98(8):2526-2534.

66. Zeidler R, Mysliwietz J, Csánady M, et al. The Fc-region of a new class of intact bispecific antibody mediates activation of accessory cells and NK cells and induces direct phagocytosis of tumour cells. Br J Cancer. 2000;83(2):261-266

67. Heiss MM, Murawa P, Koralewski P, et al. The trifunctional antibody catumaxomab for the treatment of malignant ascites due to epithelial cancer: results of a prospective randomized phase II/III trial. Int J Cancer. 2010;127(9):2209-2221.

68. Eissler N, Ruf P, Mysliwietz J, Lindhofer H, Mocikat R. Trifunctional bispecific antibodies induce tumor-specific $\mathrm{T}$ cells and elicit a vaccination effect. Cancer Res. 2012;72(16):3958-3966.

69. Riesenberg R, Buchner A, Pohla H, Lindhofer H. Lysis of prostate carcinoma cells by trifunctional bispecific antibodies (alpha EpCAM $\times$ alpha CD3). J Histochem Cytochem. 2001;49(7):911-917.

70. Ruf P, Gires O, Jäger M, Fellinger K, Atz J, Lindhofer H. Characterisation of the new EpCAM-specific antibody HO-3: implications for trifunctional antibody immunotherapy of cancer. $\mathrm{Br} J$ Cancer. 2007;97(3):315-321.

71. Chelius D, Ruf P, Gruber P, et al. Structural and functional characterization of the trifunctional antibody catumaxomab. mAbs. 2010;2(3) 309-319.

72. Seimetz D, Lindhofer H, Bokemeyer C. Development and approval of the trifunctional antibody catumaxomab (anti-EpCAM $\times$ anti-CD3) as a targeted cancer immunotherapy. Cancer Treat Rev. 2010;36(6): $458-467$.
73. Ströhlein MA, Heiss MM. The trifunctional antibody catumaxomab in treatment of malignant ascites and peritoneal carcinomatosis. Future Oncol. 2010;6(9):1387-1394.

74. Heiss MM, Ströhlein MA, Jäger M, et al. Immunotherapy of malignant ascites with trifunctional antibodies. Int J Cancer. 2005;117(3): 435-443.

75. Burges A, Wimberger P, Kümper C, et al. Effective relief of malignant ascites in patients with advanced ovarian cancer by a trifunctional antiEpCAM $\times$ anti-CD3 antibody: a phase I/II study. Clin Cancer Res. 2007;13(13):3899-3905.

76. Jäger $\mathrm{M}$, Schoberth $\mathrm{A}$, Ruf $\mathrm{P}$, et al. Immunomonitoring results of a phase II/III study of malignant ascites patients treated with the trifunctional antibody catumaxomab (anti-EpCAM $\times$ anti-CD3). Cancer Res. 2012;72(1):24-32.

77. Wimberger P, Gilet $\mathrm{H}$, Gonschior AK, et al. Deterioration in quality of life (QoL) in patients with malignant ascites: results from a phase II/III study comparing paracentesis plus catumaxomab with paracentesis alone. Ann Oncol. 2012;23(8):1979-1985.

78. Papanikolaou G, Fotopoulou C, Braicu I, et al. First surgical experience of intraperitoneal treatment with the trifunctional antibody catumaxomab (anti-EpCam $\times$ anti-CD3) for epithelial ovarian cancer. Anticancer Res. 2011;31(8):2603-2608.

79. Pietzner K, Jäger M, Schoberth A, et al. First patient treated with a re-challenge of catumaxomab in recurrent malignant ascites: a case report. Med Oncol. 2012;29(2):1391-1396.

80. Ott MG, Marmé F, Moldenhauer G, et al. Humoral response to catumaxomab correlates with clinical outcome: results of the pivotal phase II/III study in patients with malignant ascites. Int J Cancer. 2012;130(9): 2195-2203.

81. Fresenius Biotech GmbH. Two-Arm, Randomized (2:1), OpenLabel Phase II/III Study in EpCAM Positive Cancer Patients With Symptomatic Malignant Ascites Using the Trifuncitonal Bispecific Antibody Removab (Anti-EpCAM x Anti-CD3) Versus an Untreated Control Group. Available from: http://clinicaltrials.gov/ct2/show/ NCT00836654. NLM identifier: NCT00836654. Accessed August 22, 2013.

82. Fresenius biotech GmbH. CASIMAS: Catumaxomab safety phase IIIb study with intraperitoneal infusion in patients with malignant ascites due to epithelial cancers. Available at http://clinicaltrials.gov/ct2/ show/NCT00822809. NLM identifier: NCT 00822809. Accessed July 3, 2013

83. Fresenius biotech GmbH. Safety Study of Second Intraperitoneal (I.P.) Infusion Cycle of Catumaxomab in Patients With Malignant Ascites (SECIMAS), Available at http://clinicaltrials.gov/ct2/show/NCT0106 5246? term=NCT01065246\&rank=1. NLM identifier NCT 01065246 , Accessed July 3, 2013.

84. Charité - Universitätsmedizin Berlin. Single-arm, multicenter phaseII trial for catumaxomab and chemotherapy in patients with recurrent ovarian cancer to investigate the feasibility and clinical activity of initial intraperitoneal catumaxomab followed by chemotherapy regimes. Available at https://www.clinicaltrialsregister.eu/ctr-search/trial/2011004585-15/DE. IMP identification Eudra CT number 2011-004585-15. Accessed July 3, 2013.
Clinical Pharmacology: Advances and Applications

\section{Publish your work in this journal}

Clinical Pharmacology: Advances and Applications is an international, peer-reviewed, open access journal publishing original research, reports, reviews and commentaries on all areas of drug experience in humans. The manuscript management system is completely online and includes a very quick and fair peer-review system, which is all easy to use.

\section{Dovepress}

Visit http://www.dovepress.com/testimonials.php to read real quotes from published authors. 